\title{
Alteridad elemento ausente y factor común en violación de derechos humanos del socialismo del siglo XXI: Venezuela y Nicaragua
}

\author{
Mercedes Matilde Montiel de Henriquez \\ mmontiel@profesores.uhemisferios.edu.ec \\ Facultad de Derecho \\ Universidad Hemisferios \\ (Quito-Ecuador) \\ Karla Nicole Guerra Granda \\ knguerrag@estudiantes.uhemisferios.edu.ec \\ Facultad de Ciencias Sociales y Humanas \\ Universidad Hemisferios \\ (Quito-Ecuador)
}

\section{RESUMEN}

Las Investigadoras pretenden con este trabajo, establecer que la Intolerancia producto de la falta de Alteridad en el individuo, es la causa determinante de la violación de Derechos Humanos en países como Venezuela y Nicaragua, tomados como países referenciales. El aporte a lograr con este estudio es considerar que es posible la convivencia entre los hombres, aun existiendo diferencias culturales, ideológicas, religiosas o de cualquier naturaleza. Respetando en todo tiempo y momento el derecho de la persona a su libertad en variados ámbitos, siempre y cuando se cuide no afectar el derecho de los demás y de la sociedad en general.

Palabras Clave: alteridad; derechos humanos; socialismo; Venezuela; Nicaragua 


\title{
Alterity absent element and common factor in violation of human rights of 21st century socialisms: Venezuela and Nicaragua
}

\begin{abstract}
The Researchers intend with this work to establish that Intolerance, a product of the lack of Alterity in the individual, is the determining cause of the violation of Human Rights in countries such as Venezuela and Nicaragua, taken as reference countries. The contribution to be achieved with this study is to consider that coexistence between men is possible, even if there are cultural, ideological, religious differences or of any nature. Respecting at all times and at all times the right of the person to their freedom in various areas, as long as they take care not to affect the rights of others and society in general.
\end{abstract}

Keywords: alterity; human rights; socialism; Venezuela; Nicaragua

Artículo recibido: 02 noviembre. 2021 Aceptado para publicación: 28 noviembre 2021 Correspondencia: santiagou@uhemisferios.edu.ec Conflictos de Interés: Ninguna que declarar 


\section{INTRODUCCIÓN}

El examinar la intolerancia como origen de actos violentos, forma parte del aspecto fundamental a considerar en la violación de Derechos Humanos. Ahora bien, para comprender la Intolerancia en su conformación, naturaleza y existencia, se debe tomar en cuenta, a la persona detentadora de esta.

$\mathrm{Al}$ analizar la persona en sentido metafísico y moral, se aprecia en el primer caso un ser que subsiste solo y distinto, libre, autónomo, dueño de sí mismo, (Hoyos, 1991, pág. 48) en cuanto a lo moral es el ser responsable de sus acciones, capaz de superarse, de realizarse. Desde el ámbito metafísico es el ser dotado por naturaleza, de intelecto y voluntad, dueño de sus actos, con un único destino intransferible, un ser que actúa, en base a lo cual se conoce la persona, ya que sus acciones nos permiten conocerle (Hoyos, 1991, pág. 52)

En los dos sentidos antes mencionados, de la persona en sí, vienen a ser la base del individuo como sujeto de derecho, ya que, al ser capaz jurídicamente, es capaz naturalmente por su condición de ser humano, realiza actos justos, es decir su conducta se ajusta al otro, respetando las reglas jurídicas como persona jurídica que es (Hoyos, 1991, pág. 53).

Es válido considerar que la distinción conceptual, filosófica y jurídica de persona tiene su fundamento en la razón, no en la realidad conceptualizada, ya que, si todo hombre es persona en sentido filosófico, también lo es en sentido jurídico y el derecho lo que hace es reconocer y proteger su naturaleza y dignidad de persona.

Se conoce que la persona humana desde su creación posee un haber natural conformado por los bienes que le son propios, como la vida, la libertad, entre otros, los cuales tiene desde su origen, adquiridos y medidos por su naturaleza humana, los que deben ser respetados por todos, por lo que su lesión u ofensa va dirigida a la realidad personal del individuo (Hoyos, 1991, pág. 112).

Las características propias de la naturaleza humana implícitas y expresadas en todo lo que conforma al individuo, es lo que hace al hombre diferente a otros seres de la naturaleza, lo cual se da a conocer desde el aspecto mental, ético y social.

En lo propio de la naturaleza humana, se tiene la luz de la razón, elemento del derecho natural con carácter universal, no cambiante, aun considerándose las diversas culturas y civilizaciones y sobre todo la variabilidad entre los seres humanos. Lo antes indicado, 
forma parte de lo conocido como dignidad de la persona humana, el termino dignidad proviene del latín Dignitas, que significa alguien que merece algo, este merecimiento puede provenir del hecho de actuar debidamente, pero también en cuanto a la importancia que corresponde a un ser, sin que influya su comportamiento, en base a esto, toda persona humana es digna. (Hoyos, 1991, pág. 127)

La persona humana es digna tanto ontológicamente como moralmente, en el primer caso se caracteriza por el hecho de subsistir en una naturaleza de por sí perfecta. Esta subsistencia presenta un aspecto negativo referido a que el ser subsistente no está sometido a otro, no es de otro, es un ser absolutamente libre, y el positivo, relativo a que la persona es un ser que se autodetermina, autogobierna, es dueña de si y de sus actos, ambos aspectos están íntimamente relacionados y se complementan entre sí, ya que la persona humana desde su creación posee un haber natural que conforman el ser del hombre, como sus potencias, sus tendencias, las que moralmente dispone a un uso y fin determinado, disposición pesada por el buen obrar, por su inteligencia y voluntad, debidamente orientada por su conciencia bien formada. (Hoyos, 1991, págs. 128-129)

Para esta conciencia bien formada es indispensable la educación, tanto familiar como a todo nivel educativo, y esta debida conciencia responde cuando hemos obrado mal, turbándose, por lo que seguir los dictámenes de la conciencia debidamente conformada, permite un correcto proceder. Se puede afirmar que la persona es dueña de si y de su entorno, siempre y cuando no afecte a otro, que en su accionar; se trate de una persona íntegra.

La conciencia es la luz del alma, ubicada en lo profundo del ser del hombre, y de ella depende el nivel de moralidad de la sociedad, si se apaga, el hombre queda a oscuras y puede atropellarse y atropellar a otros, queda desorientado, sin guía, ve las cosas deformadas, llega a pensar que los sucesos y personas son como el las ve y no como realmente son (Carvajal, 2006)

Estos aspectos y elementos que conforman el ser del hombre no requieren justificación, porque están ahí, están implícitos en el ser de la persona humana, pero si requieren ser protegidos, porque forman parte de su derecho natural, existente antes de la legislación positiva, siendo la base del derecho positivo, el cual se activa mediante la implementación de normas, actos y decisiones en pro de la protección del sujeto de derecho. Los dos derechos mencionados conforman una unidad, ya que los derechos humanos son una 
realidad en sí, una realidad social regulada y estructurada, y el derecho positivo establece las disposiciones normativas necesarias en protección y resguardo de los derechos humanos.

En base a lo antes indicado, por medio de los derechos humanos, que se reconocen como verdaderos derechos, se pretende regular, normatizar y proteger ese derecho natural, el cual no es cedido ni otorgado por ninguna entidad, pero que debido a la reiterada violación de los mismos, surge la imperiosa necesidad de resguardarlos, auparlos y protegerlos, fundamentado en la integridad personal del individuo, debiendo ser este derecho natural de la persona humana, conservado y desarrollado en todo el ser de la persona, no sometido a ninguna condición, por lo que no puede afectarse sin que repercuta en toda la conformación del hombre, en su contexto físico, psíquico y moral como un todo.

De acuerdo con lo expuesto se puede sostener que los derechos humanos son naturales y positivos. naturales al tener su origen en la dignidad de la persona y positivos en cuanto a que su promoción, regulación, garantía y protección proceden de actos de voluntad política, permitiendo de esta manera que sean más operativos.

En la actualidad se observa en distintas partes del mundo una reiterada violencia y violación de derechos humanos por distintas razones, ideológicas, religiosas, de raza, lengua y otras más, siendo testigo la sociedad actual, de la perdida de la tolerancia, puntualmente debido a la falta de valores, en las familias y en general en la colectividad. De acuerdo con el análisis del Dr. Rómulo Lander (2015), la Intolerancia se fundamenta en la imposibilidad de mantener la "Alteridad", que no es otra cosa, que la capacidad de aceptar o tolerar las diferencias existentes en el otro.

Cada sujeto desarrolla su propio sistema de valores e ideales, y al no reconocer la validez de las diferencias de cada ser, no le es posible tolerar los distintos aspectos presentes en el otro, debiendo lidiar con el empuje natural de eliminarlo o destruirlo, en caso de no lograr convencerlo o someterlo a sus criterios, ideologías o sistema.

\section{Tolerancia y Alteridad}

De acuerdo con lo antes indicado, se pregunta ¿qué es la tolerancia? el término proviene del verbo latino "tollerare" soportar o aguantar, hoy visto como un valor o virtud del ser humano, que surge y se logra sobre todo en el entorno familiar, por lo que debe cuidarse el ejemplo que se da en la familia. 
Hoy en día, la tolerancia se complica, se hace más difícil, debido a una cultura de poca Tolerancia para todo, lo cual se va pasando de generación en generación, perjudicando la debida convivencia entre las personas.

La tolerancia permite, que lo distinto en él o del otro, no debe llevar a tenerlo como un rival o enemigo, logra el debido crecimiento de los seres humanos, es un valor mediante el cual se aprende aceptar lo distinto del otro, se evita enfrentamientos, a no crear ambientes hostiles, y que aun cuando el otro tenga ideas, criterios distintos o sea de por si diferente, debe respetarse, y esto no necesariamente dará lugar al cambio de ideas, criterios o modo de actuar, a no ser que evaluado libremente, se desee cambiar, mejorando, complementando las propias ideas, cambiándolas radicalmente o simplemente manteniendo las propias ideas, criterios o modo de proceder, sin que esto afecte la relación con el otro distinto.

La libertad del pluralismo permite considerar que no hay ninguna verdad por encima de la libre discusión racional entre personas dispuestas a entenderse, lo cual se aprecia como base de las actuales democracias liberales (Quiñones, 2019) como menciona el Padre Fernando Oscariz Prelado del Opus Dei "quien ama la libertad logra ver lo que tiene de positivo y amable lo que otros piensan. Valorar a quienes piensan distinto o de modo diverso, es una actitud que denota libertad interior y apertura de miras” y San José María fundador del Opus Dei, expresa: "De esa libertad nacerá un sano sentido de responsabilidad personal y sabréis no solo renunciar a vuestra opinión, cuando veáis que no respondía bien a la verdad, sino también aceptar otro criterio, sin sentiros humillados por haber cambiado de parecer" (Cardenas, s-f, págs. 22-23)

De otro modo al pretender imponer lo que tenemos como propio, no se respeta la libertad de los demás, se cae en una sociedad rígida, primordialmente llevada por el miedo al cambio, resultando difícil y muchas veces imposible aceptar variaciones que puedan presentarse a nivel personal o social, siempre en búsqueda de la verdad.

Al preguntarse, ¿y que es la verdad? el termino proviene del latín Veritas, es la correspondencia entre lo que pensamos o sabemos, con la realidad, lo cual no puede ser refutado racionalmente. Se habla de verdad relativa, la que se considera en cuanto a determinados criterios, como es el caso de una norma, y verdad absoluta, son las ideas o proposiciones ciertas para todas las culturas y en todos los tiempo (Significados, 2018), pudiendo afirmarse, que la verdad, es la exacta correlación con la realidad, sin considerar 
lo que las cosas sean para cada quien, sino lo que ellas son en sí mismas, por eso en la búsqueda de la verdad debemos actuar libremente, sin presiones o controles indebidos o exagerados, que solo buscan llevar nuestra acción y decisión a un determinado resultado manipulado o dirigido a un fin en particular.

Esta acción y decisión personal, al considerarse al hombre en una realidad única e irrepetible (Hoyos, 1991, pág. 66) con derechos naturales implícitos en su ser de persona, no otorgada o cedida por nada ni nadie, tomadas con la libertad existente en su ser desde su creación, pudiendo definirse esta libertad, como la facultad y derecho de toda persona para elegir responsablemente, según su capacidad de conciencia y su voluntad, el debido proceder en la sociedad.

Según lo expuesto, se observa que en la tolerancia influyen una serie de aspectos como la verdad, la libertad y un factor sumamente importante la Alteridad, que se menciona con anterioridad, y elemento determinante, que debe estar presente en el ser del individuo, desarrollando la capacidad que tiene el sujeto de discriminarse del objeto, y donde aparece el <yo soy yo> y el <tu eres tú> y por lo tanto aparece el <yo no soy tu> por lo que, al perderse la Alteridad, el sujeto pasa a no discriminar al otro como un ser diferente, y aparece el <yo no soy tu>, por lo que no se puede tolerar las diferencias existentes en el otro. (Hoyos, 1991)

En base a todo esto, los sujetos que pueden mantener la Alteridad se reconocen diferentes al otro y no ven las diferencias como una amenaza del otro, por lo que pueden tolerar las diferencias presentes en cada uno (Lander, 2015, págs. párr 3-6).

El origen etimológico procede de la palabra latina "alteritas" que proviene de los componentes alter-otro y el sufijo dad-cualidad. Es en relación al otro donde la posición del yo, filosóficamente hablando, descubre el mundo que le rodea y la presencia del otro, donde las concepciones, costumbres del otro son diferentes, viene a ser, ponernos en el lugar del otro y comprenderle.

La Alteridad propicia el dialogo, buscando el entendimiento entre las dos partes, por lo que la falta de Alteridad hace imposible la relación debido a que las posiciones chocan entre sí y no habrá entendimiento, no será posible una integración armónica, ya que el más fuerte (física, por poder, capacidad de control, entre otros) se impondrá, sin aprovechar el enriquecimiento que pueden darse mutuamente. (Porto \& Merino, 2014) 
El sentido Alteridad ligado al sentido común, propicia la armonía en las relaciones, logrando una mejor convivencia entre los hombres (Serrano B. , 2009)

Según lo indicado puede afirmarse, como lo hace la "Declaración de Principios sobre la Tolerancia" aprobada por la UNESCO en 1995, que "La tolerancia consiste en el respeto, la aceptación y el aprecio de la rica diversidad de las culturas de nuestro mundo, de nuestras formas de expresión y modos de ser humanos" (UNESCO, 1995).

La Directora General de la UNESCO Audrey Azoulay, en su mensaje por el Día Internacional de la Tolerancia el 16 de noviembre de 2017 expresa “... la tolerancia debe ser algo más que la indiferencia y la aceptación pasiva del otro. La tolerancia debe verse como un acto de liberación, por el que las diferencias de los demás, se aceptan igual que las nuestras, es un acto de humanidad, que debemos alimentar y practicar cada día en nuestra propia vida, a fin de celebrar la diversidad que nos hace fuertes y los valores que nos unen." (Azoulay, 2017).

Según lo analizado con anterioridad, la falta de Alteridad llega a nublar la conciencia y el debido discernimiento, dando lugar a la violencia en contra del otro.

Al considerar el elemento de la violencia, esta, llega a ser impactante, no solo en situaciones de conflicto, sino en diversas relaciones humanas, cualquiera sea el sexo, edad, raza e ideología

Es un comportamiento deliberado, aprendido o provocado, que da lugar a daño físico o psicológico en quien lo recibe, no es algo nuevo ya que se trata de un fenómeno histórico influido por factores familiares, políticos, culturales, económicos, psicológicos, con afectaciones en muchos casos irreparables para quienes los sufren, su entorno y la sociedad.

Tomando como punto de referencia la violencia política, el enfoque en este caso se encuentra en el agregado psicológico, en base al cual las revoluciones se explican por móviles psicológicos que desencadenan en violencia política, como la respuesta violenta de distintos movimientos ideológicos, al conflicto entre los gobiernos y los diversos grupos que luchan por el poder, lo que da respuesta a la violencia colectiva y revoluciones (Aparicio, 2015).

De acuerdo al mismo autor últimamente mencionado, la forma en que puede combatir la sociedad la violencia extrema es logrando actualizar su capacidad de resistencia y 
sufrimiento, además de involucrarse activamente en solventar las situaciones de violencia.

Como puede apreciarse en el desarrollo de este objetivo, la Intolerancia se activa, al no estar presente en el individuo la Alteridad, la cual le permite tolerar y aceptar las diferencias presentes en los otros.

Haciendo referencia al contenido del segundo Capítulo, en cuanto a considerar la eliminación de grupos humanos por Intolerancia en el presente siglo en los países en estudio, se observan aspectos similares tanto en Venezuela como Nicaragua, que serán tratados conjuntamente, resaltando las diferencia que se aprecien en el desarrollo del estudio, en base a lo cual se ha logrado obtener la siguiente información.

Hoy en día, es común que algunos gobernantes, tengan como objetivo principal de su país, el mantener su poder, dando cabida a una serie de abusos de poder y donde el pueblo es el perjudicado.

Haciendo referencia a Venezuela, y aun cuando el país ha tenido la ingrata experiencia de dictaduras en sus gobiernos, el establecimiento de un sistema criminal, altamente delictual y destructivo como el actual, empieza a verse desde 1999 con la llegada de Chávez a la presidencia, ya que este hizo una transformación total del sistema, planteando un régimen totalitario al que todos se debían someter (Ruiz, 2008).

A pesar de que la situación no era de lo mejor, Chávez logro mantenerse durante 14 años en el poder, hasta su deceso. Con la muerte de este, su segundo al mando Nicolás Maduro asumió el cargo de primer mandatario, prácticamente impuesto por Chávez, con consecuencias negativas para el país, debido a que desde que este último llego al poder, se han dado situaciones críticas en diversos ámbitos económico, de salud, políticos entre otros, para Venezuela.

En cuanto a Nicaragua, ha tenido al presidente Daniel Ortega como mandatario aproximadamente 15 años, este ha sido el que más tiempo ha estado al poder, del mal llamado socialismo del siglo XXI.

Desde su primer mandato, de 1985 a 1990 y de 2007 hasta la actualidad, implantando un gobierno autárquico y totalitario, apreciándose durante su nuevo periodo como presidente, que la situación se ha salido de control, la represión que se vive en Nicaragua solo se puede describir como una consecuencia de la grave crisis socioeconómica presente en esa nación. 
En los países antes mencionados, desde hace algunos años se presenta una crisis extrema en temas sobre los derechos humanos, lo vivido por los habitantes de estos países es inimaginable, el acceso a una vivienda digna, alimentos, salud, empleo con un sueldo justo, libertad de expresión, debido proceso, entre otros, es inalcanzable.

Lo antes expuesto, ha dado lugar a una alta emigración, ya que desde el 2015 se calcula que más de 4 millones de venezolanos han migrado en búsqueda de un mejor futuro, lo cual representa aproximadamente un $10 \%$ de la población total del país, según datos reflejados por BBC News Mundo para el 15 de enero 2020, estos cálculos revelan que dentro de los países con más cantidad de emigrantes, se tiene a Colombia con aproximadamente 1.3 millones de venezolanos, Perú con 768 mil, Chile 288 mil, Ecuador 263 mil, Argentina 130 mil y finalmente Brasil con 168 mil, estas cifras han ido en ascenso, la rapidez con la que las cifras aumentan, asombran a organizaciones como la ONU, ACNUR y la OIM, hablándose ya de Diáspora de estas poblaciones (EL PAIS , 2019, pág. s/n).

En Nicaragua la represión está presente de una manera muy grave, el gobierno patrocina grupos paramilitares que se encargan de aplacar las masas que se atreven a revelarse, se estima que producto de esto, hay más de 300 muertos, aproximadamente 2.000 heridos y cientos de personas apresadas, sin contar los desaparecidos (Human Rights Watch, 2019) En ambos países, las personas que se encuentran en prisión han sido víctimas de una serie de torturas como choques eléctricos, asfixias, golpizas desmedidas, abusos sexuales, desprendimiento de uñas, como parte de la tortura a que son sometidos, además de todas estas atrocidades se le suman torturas psicológicas (Human Rights Watch, 2019) .

Debido a la situación por la que Venezuela y Nicaragua están pasando, los ciudadanos optan por salir, pero los que no logran escapar de la crisis, debido a razones económicas, familiares, de salud, se convierten en víctimas de la completa ilegitimidad de los actos de estos gobiernos.

Según el observatorio venezolano de violencia (OVV), solo en enero 2019, la mitad de los delitos cometidos fueron por parte de la policía, estos se dieron específicamente en las manifestaciones para reprimir a los llamados por ellos insurgentes (OVV REGIÓN CAPITAL, 2019, pág. s/n).

Se estima que, desde hace casi dos décadas, en Venezuela, se han dado aproximadamente 300.000 asesinatos, pero en los seis años que Nicolás Maduro ha gobernado, más de 
1.000.000 de venezolanos han sido víctima de la llamada 'Operación de Liberación del Pueblo " siendo acusados por desacato a la autoridad (INFOBAE , 2019).

Con Nicaragua nos enfrentamos a un problema similar, pero en este caso son grupos paramilitares afines al gobierno los que se encargan de controlar cualquier acto de rebeldía al gobierno, esto ha provocado que cientos de personas estén desaparecidas, pues estos grupos apresan a cualquier llamado insurgente y no dan explicación alguna de lo que suceda con ellos. El gobierno esconde la cantidad de personas que están desaparecidas o muertas.

Lo que indigna a la sociedad tanto de Venezuela como de Nicaragua, es la impunidad que los agresores tienen, a pesar de ir contra la ley y principalmente contra los derechos humanos, Venezuela se excusa alegando, estado de excepción.

Nicaragua ha incumplido e irrespetado notoriamente los derechos humanos, ya que, de 109 decesos en el 2018, apenas 9 han sido judicializadas, esto implica que el resto ni siquiera ha iniciado un proceso judicial para esclarecer los hechos (Independientes, 2018, pág. 239).

La represión es el método que ambos gobiernos usan para mantenerse en el poder, sin importar las vidas que se pierdan, se usan los recursos que supuestamente son destinados a la protección del pueblo en su contra, las manifestaciones cada vez más se van saliendo de control, y se hacen más críticas y riesgosas.

Tanto en Nicaragua como en Venezuela, cuando se ha considerado el llamado al diálogo entre los actuales gobiernos con el pueblo, como un paso para lograr una posible solución a la situación existente, esta posibilidad, no se logra completar, ya que no se obtiene respuesta positiva alguna, siendo utilizado por estos gobiernos como un tiempo a su favor, en momentos de grave crisis.

\section{Venezuela- Nicaragua y los Derechos Humanos}

La situación presente en estas naciones es alarmante, día a día se pueden ver noticias que revelan la cruda realidad que se vive; pero ¿todo esto a qué se debe?, podría tratar de justificarse, por la total carencia de habilidades de mando de sus gobiernos, en Venezuela, agentes externos como los países que mantienen una riña silenciosa buscando controlar Venezuela y sus recursos, la nula cooperación de las fuerzas armadas al pueblo, o simplemente todas juntas. ¿Pero realmente qué es lo que sucede? Noticias sobre torturas, ejecuciones, violaciones, abuso de poder, personas que no tienen que comer, familias que 
migran, son de las principales razones existentes, y todo esto nos lleva a una conclusión: ¿acaso la empatía se ha perdido? Sobre todo, de los gobernantes en relación con sus gobernados.

Según el último reporte de la Comisión Interamericana de Derechos Humanos, la organización recibió 819 denuncias por violaciones de derechos humanos en contra de México, 536 en contra de Colombia, 67 en contra de Chile y tan sólo 53 en contra de Venezuela. Lo cual llama la atención, tratándose del país que atraviesa la peor crisis de derechos humanos de la región (Defiende Venezuela , 2019).

De lo sucedido en estos países, no es sorprendente que muchos se vean más perjudicados que otros, grupos que han sido marginados u olvidados por todos, como es el caso de los adultos mayores, niños y enfermos, tanto en Venezuela como en Nicaragua.

En Venezuela la situación de los adultos mayores es crítica, decenas de ancianos han sido olvidados en asilos por sus familiares, que justificándose en la crisis del país deciden salir de este, dejando atrás incluso a sus propios padres o abuelos, esto con tal de librarse de los infortunios que su país desencadena.

Pero el abandono, no es el problema principal que estas personas enfrentan, la falta de alimentos, medicamentos y recursos para los ancianos, es cada vez más preocupante, la pensión que los ancianos reciben es de un aproximado de 350 mil bolívares mensuales, unos $\$ 4,50$ aproximadamente al mes, teniendo en cuenta la inflación, y el abrumante precio de los alimentos que sin duda es mucho mayor al de la pensión; esto provoca que un anciano no logre satisfacer sus necesidades básicas (Made for minds ,2019).

Los índices de depresión han aumentado, y la escasez de medicamentos antidepresivos igual, como consecuencia, las cifras de suicidios de ancianos han ido en ascenso (Made for minds , 2019).

En los centros de atención para ancianos, no hay personal suficiente para el cuidado adecuado de estas personas, lo que ha hecho que los adultos mayores, que se encuentran en mejores condiciones tengan que ayudar en quehaceres del sitio, cocinando, limpiando, e incluso bañando y alimentando a los ancianos en condiciones más alarmante (Made for minds , 2019).

En Nicaragua la situación no es distinta, los beneficios que la ley de Nicaragua les ofrece a los ancianos es abundante, pero no en la práctica, pues se han dejado de lado a todo este 
sector, por lo menos en la capital, los ancianos son olvidados por todos, por el gobierno, por la sociedad y lo más triste, por su familia al igual que en Venezuela.

Un dato interesante es que el gobierno venezolano enviaba ayuda económica a Nicaragua con el fin de ayudar a los jubilados, pero desde que esto termino y la crisis se dio, el gobierno de Nicaragua se dedicó a dejar sin fondos el Instituto Nicaragüense de Seguridad Social (INSS), y esto provoco que no se logre repartir las pensiones a los jubilados (Rocha, 2017).

Las personas de la tercera edad en estos países han sido olvidadas, no existe una cultura de respeto hacia el mayor, este problema, se ha elevado potencialmente con la crisis en estos países, ya que años antes, podía darse muy esporádicamente, no de modo generalizado, teniendo como base de esta situación, una problemática social, sumado a la mala administración de los recursos por parte del gobierno, dando lugar a una tormenta, que arrastra entre otros, con los ancianos de estos países, denominándolos "abuelos huérfanos".

\section{Colectivos}

En Nicaragua todos los colectivos que han manifestado su inconformidad con el rumbo al que el gobierno está llevando al país, han sido perjudicados de algún modo, el gobierno dictatorial que lleva Daniel Ortega ha logrado silenciar a la mayor parte de la población. El gobierno se ha dedicado a silenciar y reprimir cualquier tipo de manifestación en su contra o simplemente se ataca cualquier agrupación de personas que consideren amenazante.

Es así como pequeñas manifestaciones han sido cohibidas de realizarse, ejemplo de esto es la marcha feminista, esta no obtuvo los permisos por parte de la policía, aun tratando de hacerlo por la vía legal, no se permitió hacerlo (EL COMERCIO, 2018).

Según informes del 2019, tan solo en septiembre y octubre se informó de más de 100 detenciones arbitrarias y esto es una evidente muestra de las violaciones a los derechos humanos pues los derechos vulnerados son: derecho a la libre movilización, derecho a la libertad individual, derecho a la integridad personal, derecho a manifestarse pacíficamente, pudiendo estableces muchos más (Cruz, 2019).

En Venezuela se trata de bandas de delincuentes armadas por el gobierno, para controlar por la fuerza y con amedrentamiento barrios completos como Petare en Caracas y San Francisco en Maracaibo, las dos principales ciudades del país y las de mayor población. 


\section{Infantes}

El otro grupo de persona mayormente afectadas por la crisis de estos países en estudio, son los niños y adolescentes de ambos países

Muchas familias se separan, padres que dejan a sus hijos al cuidado de otros, con el fin de buscar mejorar sus ingresos y de este modo subsistir, y cubrir las necesidades más elementales del ser humano como alimentos, medicamentos, techo, pero los niños y/o adolescentes que se quedan, sufren en el ámbito afectivo por la separación de sus padres, y que aun cuando los padres desde donde estén, les envíen dinero y bienes para mejorar sus condiciones de vida en estas naciones críticas, nada suple la presencia, orientación y amor de sus progenitores.

Las cifras de niños al cuidado de otros que no son sus padres son increíbles, aproximadamente 930.000 niños están en esta situación, los que quedan a su cargo enfrentan otro tipo de problemática jurídica, de atención y manutención de los niños y/o adolescentes a su cargo (Bordan, 2020).

Los niños que quedaron en situación de orfandad o las personas con las que los dejaron y no pueden continuar haciéndose cargo, por razones económicas (son una boca más) de dedicación y tiempo (deben ubicar otros ingresos para cubrir las necesidades primarias del grupo familiar), se ven ante dos alternativas, la primera son los albergues, que están acogiendo más de 1.300 niños, siendo aproximadamente unos 86 albergues, que no logran mantenerse adecuadamente, rebasando la cantidad de niños que estos lugares pueden recibir (El Mercurio Web, 2018).

Debido a esto, algunos de los niños solo acuden a los patios de los alberges a buscar agua, tomar una ducha y regresar a su vida en las calles en las que tienen que luchar por la comida (El Mercurio Web, 2018).

La cantidad de niños en las calles es cada vez más preocupante, estos niños han ideado una manera para lograr abastecerse de comida, esta es la conformación de pandillas, donde merodean las calles con cuchillos, buscando entre la basura comida y compartiendo esta con los miembros de la pandilla, cabe recalcar que estas están conformadas por niños y adolescentes entre los 6 y 17 años, dando inicio y propensión a una futura vida delictiva ( El Mercurio Web , 2018).

Sumado a la necesidad prioritaria de alimentarse, los niños y jóvenes se ven expuestos a otro tipo de peligro, las drogas, que son una de las principales problemáticas aparte de la 
falta de alimento, buscar comida para satisfacer sus necesidades básicas, pero además buscan la manera de conseguir dinero para el consumo de drogas, llegando en algunos casos hasta a la prostitución con tal de satisfacer esta adicción (EFE, 2018 ) .

La situación de los menores es similar tanto en Venezuela como en Nicaragua-

La alta comisionada de los derechos humanos para Naciones Unidas Michael Bachelet, informo que Maduro ha violado los derechos fundamentales, criminalización de la protesta, restricciones a libertad de expresión, éxodo masivo y deserción escolar por falta de alimentación. Ha mencionado que el alcance y la gravedad de las crisis en los alimentos, la atención médica y los servicios básicos, no han sido plenamente reconocidos por las autoridades, por lo que las medidas que adoptaron son insuficientes (ACNUDH, 2018).

Bachelet informo que su oficina, ha documentado numerosas violaciones de derechos humanos y abusos cometidos por las fuerzas de seguridad y grupos armados progubernamentales, es decir colectivos armados, incluyendo el uso excesivo de la fuerza, homicidios, detenciones arbitrarias, torturas y malos tratos bajo custodia, amenazas e intimidaciones (ACNUDH, 2018).

El estado debe garantizar el respeto a los derechos humanos, anteponiéndolos a cualquier situación, el estado debe implementar medidas y usar todos los recursos disponibles en la defensa de estos.

Realizando un análisis comparativo entre los gobernantes de estos dos países, Nicolás Maduro y Daniel Ortega, quienes dirigen y toman las decisiones y acciones en estos países, puede observarse entre ambos, varias similitudes, donde puede apreciarse elementos personales, familiares y sociales que permiten calificarlos como Resentidos Sociales.

Definiendo este término, se refiere a individuos que en su niñez o juventud han sufrido situaciones de desigualdad, injusticia, corrupción, han sido abusados por el poder de turno o el ámbito social o familiar donde se han desarrollado.

Individualmente, se expresa en impotencia, rencor, odio o rechazo en relación a quienes el resentido considera culpables de su situación, se sienten afectados por su condición socioeconómica, familiar e individual, sumado al abuso de poder.

En el caso de Nicolás Maduro Moro, nació en Caracas- Venezuela el 23 de noviembre de 1962, de padres emigrantes colombianos (existiendo la información no oficial que nació 
en Colombia). Creció en la Parroquia popular El Valle en el oriente de Caracas, de origen muy humilde. En sus estudios llego a secundaria, sin que se tenga conocimiento ni prueba,de haber obtenido la conclusión de estos estudios.

Milito en la liga socialista de ideario marxista-leninista-maoísta, practicantes de lucha contra el gobierno de Rómulo Betancourt. Su padre Nicolás Maduro García, militaba en una facción disidente del ala izquierda del partido Acción Democrática, pero Maduro hijo se inclinó a las ideas procastristas. Sin formación universitaria y casi sin ninguna educación de estudios en general entra a trabajar en el Metro de Caracas, como chofer de servicio de autobuses metropolitanos Metrobús.

Según información del diario colombiano Diario Huilia, en su edición del 19 de marzo de 2013, Nicola Maduro hijo, vivió en la Habana -Cuba entre 1986 a 1987, como alumno de la Escuela Superior Nico López, institución dedicada a la formación en el partido comunista de Cuba y preparación de futuro dirigentes políticos de agrupaciones ideológicamente afines de América del Sur, Central, el Caribe y África.

En Venezuela llego a ejercer varios cargos políticos durante los gobiernos de Hugo Chávez, tales como: Diputado de la Asamblea Constituyente en 1999-Ministrno del Poder Popular para asuntos exteriores en 2006- Vicepresidente Ejecutivo en 2012- Presidente de Venezuela ininterrumpidamente desde 2013 hasta hoy.

Todos estos cargos designados dentro del sistema del Socialismo del siglo XXI, obtenidos de manera fraudulenta y con el apoyo de países comunistas.

En relación con Daniel Ortega de Nicaragua, nació el 11 de noviembre de 1945 en La Libertad, Departamento de Chonbala Nicaragua, sus padres fuertes opositores al régimen de Anastasio Somoza, sufriendo su madre Lidia Saavedra encarcelamiento por parte de este gobierno, manteniéndose toda la familia contraria a esta dictadura.

Daniel Ortega fue detenido a los 15 años por sus actividades políticas, estando encarcelado en 1967 por el lapso de 7 años, al robar una sucursal del Bank of American, siendo exilado a Cuba, donde fue entrenado en guerrilla, regresando a Nicaragua para unirse al Frente Sandinista de Liberación Nacional (FSLN) y luchar contra el régimen de Somoza.

No concluyó sus estudios universitarios en Derecho en la Universidad Centroamericana de Managua. Luego de expulsado Somoza, Ortega coordinaba la reconstrucción nacional 
del país, siendo elegido Presidente en 1984, manteniéndose en el poder desde esa fecha hasta la actualidad de modo fraudulento y dictatorial, al igual que Maduro en Venezuela. Consideraciones de aspectos comunes en ambos gobernantes

Desde muy jóvenes fueron sometidos a maltratos, presiones tanto físicas como económicas y sociales

Ambos fueron adoctrinados bajo sistemas opresivos de adoctrinamiento en acciones político-militares

Escasa formación educativa institucional

Idearios comunistas radicales

Por las acciones y presiones vivenciadas, se dio en ellos Resentimiento Social

\section{CONCLUSIONES}

Todos estos aspectos permiten evidenciar que en ambas personas existe una falta de Alteridad, que como hemos expresado es lo que permite aceptar otras diferencias de diversa naturaleza, además de la nuestra

Dando lugar a situaciones críticas, denigrantes y generalizadas que alcanzan a toda una población, país o entorno, sin medirse el daño que causan ni la violación de los derechos al resto de los individuos.

En base a esto, es determinante el cuidado y atención que se mantenga en relación a los niños y jóvenes, ya que de otro modo se podría estar propiciando la existencia de persona con este conflicto, que se está demostrando pueden llevar al caos a naciones completas como el caso de Hitler en la Segunda Guerra Mundial y hoy en día, diversos países de América

Debe buscarse la manera de preservar el crecimiento y sana formación de niños y jóvenes, aun en situaciones críticas como guerras, revoluciones, guerrillas, no permitir sean sometidos a presiones de tal naturaleza que les afecte su adecuado crecimiento no solo físico sino psíquico, emocional, sentimental, afectivo, a fin de lograr individuos que puedan convivir con todos y aceptar a todos dentro de un debido entorno ético y moral, esta sería la forma de poder mirar al mundo con ojos de Esperanza, como expreso en una oportunidad San Juan Pablo II. 


\section{REFERENCIAS BIBLIOGRAFICAS}

El Mercurio Web . (28 de Marzo de 2018). El Mercurio Web . Obtenido de https://elmercurioweb.com/noticias/2018/3/28/pandillas-de-ninos-usan-armaspara-asegurar-la-comida-que-dejan-en-la-basura

ACNUDH.

ohchr.org.

Obtenido

de https://www.ohchr.org/Documents/Countries/VE/VenezuelaReport2018_SP.pdf Aparicio, L. (24 de Agosto de 2015). El origen de la violencia en las sociedades humanas. Obtenido de http://www.ieee.es/Galerias/fichero/docs_opinion/2015/DIEEEO902015_OrigenViolencia_Sociedades_L.Aparicio-Ordas.pdf

Azoulay, A. (16 de Noviembre de 2017). Mensaje de la Sra. Audrey Azoulay, Directora General de la UNESCO. Obtenido de UNESCO: http://www.unesco.org/new/es/unesco/events/prizes-andcelebrations/celebrations/international-day-for-tolerance/

Bordan. (01 de Febrero de 2020). Venezuela al Dia. Obtenido de https://venezuelaaldia.com/2020/02/01/al-menos-930-000-ninos-en-venezuelaestan-al-cuidado-de-parientes-debido-a-la-diaspora/

Cardenas, A. (s-f). Meditaciones- Octavario por la unidad de los cristianos. Madrid.

Carvajal, F. (2006). Habla con Dios . Madrid: Ediciones Palabras .

Cruz, A. (08 de Noviembre de 2019). La Prensa. Obtenido de https://www.laprensa.com.ni/2019/11/08/nacionales/2608917-mas-de-100opositores-fueron-detenidos-en-los-ultimos-dos-meses-denuncia-colectivonicaragua-nunca

Defiende Venezuela . (2019). Defiende Venezuela. Obtenido de https://www.defiendevenezuela.org

EFE. (21 de Diciembre de 2018 ). Portafolio . Obtenido de https://www.portafolio.co/internacional/los-ninos-en-la-crisis-venezolana524676

EL COMERCIO. (24 de NOVIEMBRE de 2018). EL COMERCIO. Obtenido de https://www.elcomercio.com/actualidad/opositores-feministas-suspensionmarcha-nicaragua.html 
El Mercurio Web. (04 de Marzo de 2018). El Mercurio Web. Obtenido de https://elmercurioweb.com/noticias/2018/3/4/nios-desamparados-deambulantras-salida-de-sus-padres-del-pas

EL PAIS . (7 de JULIO de 2019). EL PAIS INTERNACIONAL. Obtenido de https://elpais.com/internacional/2019/06/07/actualidad/1559911612_775139.htm 1

Hoyos, C. (1991). El concepto de persona y los derechos humanos. Bogota: Universidad de la Sabana .

Human Rights Watch. (19 de JUNIO de 2019). Human Rights Watch. Obtenido de https://www.hrw.org/es/report/2019/06/19/brutal-represion/torturas-tratoscrueles-y-juicios-fraudulentos-contra

Independientes, G. I. (2018). Informe sobre los hechos de violencia ocurridos entre el 18 de abril y el 30 de mayo del 2018. Mexico: GIEI (Grupo Interdisciplinario de Expertos Independientes ). Obtenido de https://gieinicaragua.org/gieicontent/uploads/2018/12/GIEI_INFORME_DIGITAL.pdf

INFOBAE . (3 de febrero de 2019). INFOBAE . Obtenido de https://www.infobae.com/america/venezuela/2019/02/03/los-escalofriantesnumeros-de-la-violencia-en-venezuela-mas-de-300-000-asesinados-en-20-anosde-revolucion-chavista/

Lander, R. (23 de Agosto de 2015). Origen de la Intolerancia . Obtenido de Rómulolander.org: http://www.romulolander.org/origen-de-la-intolerancia/

Made for minds . (02 de Julio de 2019). Obtenido de https://www.dw.com/es/el-dramade-envejecer-en-venezuela/a-49447012

OVV REGIÓN CAPITAL. (07 de Marzo de 2019). OBSERVATORIO VENEZOLANO DE VIOLENCIA . Obtenido de https://observatoriodeviolencia.org.ve/regioncapital-funcionarios-policiales-cometieron-la-mitad-de-los-delitos-ocurridos-enenero/

Porto, J. P., \& Merino, M. (2014). Alteridad . Obtenido de Definición.de: https://definicion.de/alteridad/

Quiñones, J. G. (2019). La intolerancia disfrazada de virtud.

Rocha, J. L. (11 de Octubre de 2017). CETRI. Obtenido de https://www.cetri.be/Movimientos-sociales-en-Nicaragua?lang=fr 
Ruiz, F. J. (2008). Revolución es la profesión? Hugo Chavez y su impacto en el periodismo latinoamericano. En Las frágiles democracias latinoamericanas (pág. 309 ). El mercurio .

Serrano, B. (2009). Las posibilidades del Sentido y la Alteridad Radical: un recorrido arqueológico por el pensamiento de Lévinas. Daimon: Revista Internacional de Filosofía, 81-96.

Significados. (03 de Septiembre de 2018). Significados. Recuperado el 2019, de https://www.significados.com/verdad/

UNESCO. (1995). Declaración de Principios sobre la Tolerancia. París: Naciones Unidas .

Villegas, I. (25 de 09 de 2012). Listin Diario. Obtenido de https://listindiario.com/lavida/2012/09/25/248436/el-resentimiento-social-y-sus-efectos 